DOI: $10.4274 /$ tpa.46.73

\title{
Yenidoğan ve sütçocuğunun epileptik sendromları
}

\author{
Epileptic syndromes of newborn and infant
}

\author{
Meral Özmen, Burak Tatlı, Barı̧ Ekici \\ Istanbul Üniversitesi Istanbul Tıp Fakültesi Çocuk Sağı̆̆ı̆ ve Hastaılıları Anabilim Dalı, Çocuk Nörolojisi Bilimdall, Istanbul, Türkiye
}

\section{Özet}

Epileptik sendromlar başlangıç yaşı, nöbet tipi, elektroansefalografi bulguları, eşlik eden klinik özellikler ve tedavi yanıtı ile özgün durumlardır. Uluslararası Epilepsiyle Savaş Derneği epileptik sendromların tanınmasını sağlamak amacıyla yaşa bağlı bir sınıflandırma yapmıştır. Epileptik sendromların tanınmaSı, uygun tanısal tetkik ile tedavi tercihine ve hastaların seyrinin tahmin edilebilmesine olanak sağlar. (Türk Ped Arş 2011; 46: 191-5)

Anahtar sözcükler: Elektroansefalografi, epileptik sendromlar, sütçocuğu, yenidoğan

\section{Summary}

Epileptic syndromes are categorized by age of onset, seizure types, clinical features, electroencephalographic findings, and response to treatment. The International League Against Epilepsy uses the age-related expression of these syndromes, allowing easy identification. Early recognition and identification of epileptic syndromes is essential to provide valuable information on management and prognosis. (Turk Arch Ped 2011; 46: 191-5)

Key words: Epileptic syndromes, electroencephalography, newborn, infant

\section{Giriş}

Epileptik sendromun tanımı, "belirti ve bulgularıyla özgün bir epileptik durum" olarak yapılabilir. Çocuklarda epileptik sendromlar ortaya çıkış yaşı, nöbet tipi, elekroansefalografi (EEG) bulguları, eşlik eden klinik özellikler göz önüne alınarak tariflenmiştir (1). Epileptik sendromların tanınması, uygun tanısal tetkik ile tedavi tercihine ve hastaların seyrinin tahmin edilebilmesine olanak sağlar. Bu derlemede yenidoğan ve sütçocukluğu döneminde görülen epileptik sendromlarının tanı, tedavi ve seyri irdelenecektir.

\section{Yenidoğan dönemi epileptik sendromları}

Epileptik olayların sık görüldüğü yenidoğan döneminde epileptik sendromlar oldukça nadirdir. Uluslararası Epilepsi ile Savaş Derneği'nin (ILAE) 1989 sınıflandırmasında ve epileptik sendromlar çalışma grubunun 2006 raporunda yenidoğanlarda dört epileptik sendrom tariflenmiştir $(2,3)$.

\section{Selim idiyopatik yenidoğan nöbetleri}

Ailesinde nöbet öyküsü olmayan sağlıklı yenidoğanların 4. ve 6. günleri arasında görülen "Beşinci gün nöbeti” olarak da adlandırılan nöbetlerdir. Tüm yenidoğan nöbetlerinin yaklaşık \%7'sini oluşturan bu durum erkeklerde kızlara göre iki kat daha sık görülür $(4,5)$. Apnenin eşlik edebildiği klonik status epileptikus en belirgin nöbet tipidir. Nöbetler sık tekrarlayan tek taraflı klonik nöbetler veya kesintisiz şekilde iki saat ile gün gün sürdükten sonra kaybolur ve tekrarlamaz. Etiolojide çinko eksikliği, viral enfeksiyonlar ve beslenme tercihlerinden şüphelenilmektedir (6).

Nöbet EEG'de sentrotemporal bölgede daha belirgin ritmik diken-yavaş dalgalar olarak saptanır. Nöbetler arasındaki EEG'de 4-7 Hz'lik taraf değiştiren teta dalga akvitesi görülmesi hastalık için belirleyicidir $(7,8)$. Uzamış nöbetler benzodiyazepinler ve fenitoin ile durdurulabilir. Nöbetler kendiliğinden gerilediği için idame tedavisi gerektirmez. Hastalığın seyri çok iyidir. Status epileptikus tablosuna rağmen hastalarda nöro-bilişsel etkilenme veya tekrarlayan nöbetler gözlenmez $(4,5)$.

\section{Selim ailevi yenidoğan nöbetleri}

Selim ailevi yenidoğan nöbetleri otozomal baskın (dominan) kalıtılan nadir bir kanalopatidir. Nöbetler hayatın ilk haftasında sıklıkla da ikinci veya üçüncü gününde ortaya çıkar. Tonik duruş veya apne ile başlayan nöbetler gözlerde kayma,

Yazışma Adresi/Address for Correspondence: Dr. Barış Ekici, İstanbul Üniversitesi İstanbul Tıp Fakültesi Çocuk Sağlığı ve Hastalıkları Anabilim Dalı, Çocuk Nörolojisi Bilimdalı İstanbul, Türkiye E-posta: ekicibaris@yahoo.com Geliş Tarihi/Received: 07.11.2010 Kabul Tarihi/Accepted: 02.12.2010 
motor otomatizmalar ve klonilerle devam eder. Klonik kasılmalar çoğu kez tek taraflıdır (9).

Etyolojiden voltaj bağımlı potasyum kanalları KCQ2 ve KCQ3'ün genlerindeki mutasyonlar sorumlu tutulmaktadır. Bu kanallar dinlenmedeki membran potansiyelini belirleyen M-akımını düzenlerler $(10,11)$.

Nöbette EEG'de asimetrik diken-dalga kompleksleri görülür. Nöbetler arası dönemde yenidoğanların fizik bakısı ve EEG bulguları normaldir (8). Hastaların çoğunda sorunsuz gebelik ve doğum öyküsü vardır.

Nöbetler ilk haftanın sonunda kaybolur. İzlemde hastaların yaklaşık \%16'sında ateşli veya ateşsiz nöbet bildirilmiştir. Hastalarda nöro-bilişsel gelişim etkilenmez $(9,10)$.

\section{Ohtahara sendromu}

Yenidoğanlardaki ciddi epileptik ansefalopati tablolarından biri olan Ohtahara sendromu ilk kez 1976'da tanımlanmıștır. Hastalık ilk üç ayda ardışık tonik kasılmalarla başlar. Tonik kasılmalar 1-10 sn süren fleksör veya ekstansör hareketler olup günlük nöbet sayısı 100'ü geçebilir. Olguların üçte birinde fokal klonik nöbetler de görülür. Elekroansefalografide 2-6 sn. süren yoğun yüksek voltajlı mültifokal diken-dalgaları takip eden 3-5 sn. süreli voltaj baskılanması (Börst-Supresyon) saptanır (12,13).

Etyolojiden çoğu kez yapısal beyin anomalileri sorumludur. Hemimegansefali, poransefali, Aicardi sendromu, OliverDentat displazisi, mamilar cisim agenezisi, serebral disgenezi ve kortikal displaziler hastalıkla ilişkilendirilmiştir. Kriptojenik formların görüntüleme yöntemleri ile saptanamayan mikro disgeneziler veya nöronal göç anomalilerinden kaynaklandığı düşünülmektedir (14).

Ohtahara sendromunda nöbetler tedaviye dirençlidir. Tedavide kullanılan valproik asit, benzodiyazepinler, ACTH, kortikostroidler ve yüksek doz pridoksal fosfata yanıt sınırıdır. Ketojenik diyetin etkisi ise tartışmalıdır (15). Özellikle kortikal dizplazili olgularda epilepsi cerrahisi nöbet sayısını düşürebilmekte ve psikomotor gelişimi desteklemektedir (16).

Yaşla beraber nöbetler tipik infantil spazmlara; EEG bulguları ise hipsaritmiye dönüşür. Okul çağına ulaşabilen hastaların yarısında nöbet kontrolü sağlanabilmesine rağmen, çoğunda psikomotor gerilik gözlenir (17).

\section{Erken miyoklonik ansefalopati}

Erken miyoklonik ansefalopati (EMA) hayatın ilk üç ayında başlayan EEG'de voltaj baskılanmasının görüldüğü kötü gidişli bir epileptik durumdur. Erken başlangıç yaşı, ansefalopatik seyri, tedaviye dirençli oluşu ve EEG bulgularıyla Ohtahara sendromuyla benzerlikler gösterir (18). Miyokloniler yoğun olarak ekstremitelerin distal uçlarında, yüz ve göz kapaklarında ortaya çıkmaktadır. Kısmi nöbetler de miyokloniler kadar sık görülür. Bu nöbetler gözlerde kayma, apne ve asimetrik tonik duruş şeklindedir. Hastalıkta görülen diğer bir nöbet tipi ise tonik spazmlardır (19).

Olguların çoğunda altta yatan neden açığa çıkarılamamaktadır. Yapısal bozuklukların ön planda olduğu Ohtahara sen- dromonun aksine metabolik veya genetik hastalıklar EMA ile ilişkilendirilmiştir. Non-ketotik hiperglisinemi, propiyonik asidüri, metilmalonik asidemi, D-gliserik asidemi, sulfit veya ksantin oksidaz eksikliği, Menkes hastalığı ve Zellweger sendromu bu hastalığa neden olduğu bilinen başlıca metabolik bozukluklardır. Uyanıklık EEG'sindeki yavaş zemin aktivitesine eşlik eden mültifokal diken dalgalar, uykuda yerini voltaj baskılanması görünümüne bırakır (17-20).

Standart ilaçlar ve kortikosteroidlerin nöbetlere etkisi sınırIıdır. Yaşla beraber miyokloniler azalmakla beraber kısmi nöbetler direnç kazanır. Hastaların önemli bir bölümü erken yaşlarda kaybedilmektedir. Sağ kalanlarda dirençli nöbetler ve ciddi psikomotor gerilik görülür (21).

\section{Sütçocuğu epileptik sendromları}

Süt çocukluğu döneminde görülen epileptik sendromlar çoğu kez ilerleyen yaşlarda devam eden nöbetlere ve bilişsel etkilenmeye yol açmaktadır. Bu dönemin epileptik sendromlarından West sendromu, Dravet sendromu ve Doose sendromu ayrıca epileptik ansefalopatiler olarak da sınıflandııımaktadır.

\section{West sendromu}

Süt çocukluğunun en tanınmış epileptik sendromu kuşkusuz West sendromudur (WS). Hastalığın sıklığı 100000 canlı doğumda 25 olup en sık hayatın 4-7 ayları arasında ortaya çıkar (22). İlk kez 1841 yılında West tarafından tanımlanan bu durum; infantil spazm olarak adlandırılan tipik nöbetler, EEG'de hiparitmi bulgusu ve psikomotor gerilik ile belirgindir (23). Tipik spazmlar vücudun iki tarafında tüm kas gruplarını genellikle simetrik tutan, 2-5 saniye süren fleksör/ekstansör kasılmalar şeklindedir. Spazmlar genellikle 530 saniye aralıklı seriler halinde görülür. Çoğu uyku ile ilişkilidir ve uyanma anında veya hemen sonrasında görülür (24). Video-EEG ile yapılan çalışmalarda tipik spazmlardan başka, semptomatik etiolojili olgularda saptanan, izole kas gruplarında (yüz, göz, boyun, omuz gibi) çok küçük kasılmalarla seyreden "subtle spazm" diye adlandırılan birçok atipik spazmlar tanımlanmıştır. Bu türden atipik spazmları tanımak çok zordur, kolaylıkla gözden kaçabilir. Aynı tipte tekrarlayıcı nitelikte hareketler gözlenen ya da gelişimsel duraklama olan her süt çocuğunda WS akla gelmelidir (25). Uyanıklık EEG'sine hipsaritmi; yaygın düzensiz yüksek voltajlı yavaş dalgalara karışan mültifokal dikenler, çoklu dikenler, keskin dalgalar ile belirgin iken uykuda hipsaritmi; periyodik, yaygın düzensiz yavaş dalga, diken dalga paroksismaları olarak belirir $(23,24)$. Psikomotor gerilemede "vizüel agnozi" ve bilişsel bozulma en belirgindir. Bilşsel bozulma hem epileptik nöbetler, hem de hipsaritmi ile ilişkilidir $(26,27)$.

Etyolojik nedene göre WS semptomatik, kriptojenik ve idiyopatik olarak üçe ayrılır. Hastaların yaklaşık \%75'i nöbetlerin kortikal malformasyonlar, perinatal olaylar, nörokütanöz sendromlar (tüberoskleroz, Sturge Weber...), kromozomal bozukluklar ve metabolik hastalıklara bağlı geliştiği bulgu veren gruptandır. Kriptojenik grupta allta yatan neden ortaya konulamaz- 
ken, idiyopatik WS'de hastaların nöbetler öncesinde psikomotor gelişimleri normaldir $(23,24)$.

Seyir altta yatan nedenle ilişkili olmakla beraber, hastaların \%80'inde değişik düzeylerde bilișsel etkilenme gelişir. İdiyopatik gruptaki çocuklarda seyir daha iyidir. West sendromlu çocukların yaklaşık \%50-70'inde infantil spazmlar dışındaki nöbet tipleri de görülür. Bu hastalarda yaşla beraber tonik nöbetlerle giden Lennox-Gestaut sendromu gelişebilir. Psikomotor gelişimi olumsuz etkileyen en önemli etmenlerden biri de tanı veya tedavideki gecikmelerdir (24-27).

West sendromunun en etkin tedavisi ile ilgili kesin kanıtlar olmamakla beraber, adrenokortikotropin veya prednizolon kullanılan hormonal tedavi idiyopatik olgularda standart olarak kullanılmaktadır. Tüberoskleroz ve kortikal malformasyonlarla ilişkili WS olgularında yüksek doz vigabatrinin daha etkili olduğu bilinmektedir $(28,29)$. Karşılaştırmalı çalışmalar hormonal tedaviye yanıtın daha iyi ve hızlı olduğunu, vigabatrinin ise daha iyi tolere edilebildiğini göstermiştir (30). Ketojenik diyet ile hastaların 2/3'ünde infantil spazmların kontrol altına alınabildiği ve diyetin yan etkilerinin adrenokortikotropinden daha az olduğu bildirilmiştir (31). Diğer tedavi seçenekleri ise piridoksin, valproik asit ve topiramattır.

\section{Selim miyoklonik epilepsi}

Selim miyoklonik epilepsi öncesinde sağıklı altı ay ile üç yaşındaki çocuklarda kısa miyoklonik nöbetlerle ortaya çıkan nadir idiyopatik bir epilepsidir. Hastaların 1/3'ünde ailede epilepsi veya ateşli nöbet öyküsünün bulunması etiolojide genetik etmenleri düşündürtmektedir. Miyokloniler vücudun üst yarısında daha belirgindir, başta ani fleksiyon ve kollarda yukarı veya yanlara ekstansiyon şeklinde görülür. Gözler geriye dönebilir ancak bilinç hiçbir zaman tam kaybolmaz, sadece, çok nadiren, bacaklar etkilendiği zaman çocuk yere düşer. Kümeler halinde gözlenen nöbetler uykuda veya uyanıklıkta ortaya çıkabilir. Nöbetler arasındaki EEG'de patoloji saptanmazken nöbet sırasındaki EEG'de diken, çoklu diken-dalga grupları görülür $(32,33)$. Hastaların önemli bir kısmında hafif bilişsel etkilenme gelişir (34). Nöbetler çoğu kez valproik asit tedavisine iyi yanıt verir. Klobazam ve levetirasetam etkinliği bilinen diğer ilaçlardır (35).

\section{Selim ailevi ve ailevi olmayan süt çocukluğu nöbetleri (Vigevano-Watanabe Sendromu)}

Süt çocukluğunun selim nöbetleri en sık 4-6 ay arasında görülür. Bildirilmiş 100 kadar olgu olmakla beraber gerçek sayının bunun çok üzerinde olduğu düşünülmektedir. Ailede selim süt çocukluğu nöbeti öyküsü olan ailevi tip Vigevano tarafından tariflenmiştir (36). Ailevi yenidoğan nöbetlerinin aksine kanalopatiden çok heterojen genetik bağlantı gösteren otozomal baskın kalıtım söz konusudur (37). Nöbet anında; psikomotor aktivite duraklar, bilinç bozulur, baş ve gözler yavaşça bir tarafa döner, genel hipertoni ve vücudun bir yarısından başlayarak yaygınlaşan klonik atımlar gelişir. Nöbet başlangıç yeri ve tutulan taraf nöbetten nöbete değişebilir. Nöbetler kısa sürer, beş dakikayı geçmez. Nöbetler arasındaki EEG nöbet kümelerin- den önce ve sonraki dönemlerde normaldir. Nöbet sırasındaki EEG'de giderek ilerleyen aynı tarafa ve karşı hemisfere yayılan ve amplütüdü yükselen fokal deşarjlar saptanır (38). Kısa süreli antiepileptik tedaviye yanıt oldukça iyidir. Watanabe bildirdiği hastalarda karbamazepine iyi yanıt almış (39), Vigevano ise daha çok valproik asit ile fenobarbital kullanmıştı. Hastaların nöro-bilişsel gelişiminde etkilenme beklenmez (40).

\section{Dravet sendromu}

Süt çocuğunun ağır miyoklonik epilepsisi çoğunlukla bir yaşından önce ortaya çıkar. Öncesinde nöromotor gelişimi normal olan çocuklarda hastalık uzamış ateşli yaygın veya tek taraflı klonik nöbetler ile başlar. Ateşli hastalıklar, aşılar ve sıcak su banyosu nöbetleri tetikleyebilir. Miyokloniler, atipik "absans" ve kısmi nöbetler iki yaşında görülmeye başlar. Bazı olgularda nöbetler başlangıçtan beri ateşsiz olabilir ve yine bazı olgularda miyoklonik nöbetler olmayabilir.

Erken dönemde nörolojik gelişimi yaşına uygun olan hastaların özellikle ikinci yaşında bilişsel işlevleri ve davranışları etkilenmeye başlar. Etkilenen çocukların \%60'ında ataksi, \%20'sinde piramidal bulgular görülür (40).

Hastaların yaklaşık 2/3'ünde SCN1A geninde mutasyonlar saptanmışıı. Bu gen voltaj bağımlı bir sodyum kanalını kodlar (41). Yaygın epilepsi febril nöbet + febril konvülsiyon jeneralize epilepsi (GEFS+) ve sütçoçuğunun ağır idiyopatik yaygın epilepsisinde de bu kanaldaki mutasyonlar saptanmıştır. Febril konvülziyon jeneralize epilepsi + son dönemde tariflenmiş otozomal baskın geçişli, hastanın ailesinde değişik nöbet fenotipleri öyküsünün olduğu bir sendromdur. Ateşli nöbetlerin altı yaşından sonra da görülmeye devam ettiği bu durum SCN1A mutasyonları yelpazenin hafif ucundayken Dravet sendromu ağır ucundadır (42).

Nöbet aralarında EEG ilk yılda genellikle normaldir, nadiren kendiliğinden veya ışık uyarısı ile beliren diken dalga deşarjları görülebilir. Epileptiform EEG bulguları 2-3 yaşlarında belirir; "börstler" halinde yaygın çoklu dikenler, çoklu diken yavaş dalgalar veya diken yavaş dalgalar görülür. Deşarjlarla birlikte miyokloni olabilir, olmayabilir. Zemin aktivitesi normal, düzensiz olabilir, 4-5 Hz monomorf teta ritmi gösterebilir (43).

Nöbetler bilinen antiepileptiklere yanıtsızdır. Valproik asit ve klobazam en etkili ilaçlardır. Yeni bir antiepileptik olan stiripentolun erken dönemde tedaviye eklenmesinin nöbet sıklı̆̆ını ve şiddetini azaltığı bildirilmektedir $(40,44)$. Ketojenik diyet nöbet sıklığını \%50-\%75 oranında azaltabilmektedir (45). Status epileptikus gelişiminden kaçınmak için uzayan nöbetlerde rektal diyazepam uygulaması yapılabilir. Miyokloniler beş yaşından önce, karmaşık kısmi nöbetler beş yaşından sonra kaybolur, fakat yaygın veya ikincil yaygın tonik-klonik nöbetler ısrar eder. Nöropsikolojik gelişim her zaman kötüdür, sık nöbetler ve status atakları bilişsel gelişimi engeller (46).

\section{Miyoklonik-astatik epilepsi: Doose sendromu}

Miyoklonik astatik epilepsi öncesinde, sağılılı 2-5 yaş arası çocuklarda, EEG'de yaygın diken-keskin dalga aktivitesinin eşlik ettiği tekrarlayan yaygın tonik-klonik nöbetler ile başlar. 
Düșmelerin ve "absans"ların da birlikte görüldüğü miyokloniler hastalığın seyrinde belirginleşir. Simetrik miyoklonik atımlar ve bunu izleyen ani kas tonus kaybı miyoklonik-astatik nöbetler olarak adlandırılır. Nöbetlerin yol açıı̆ı düşmeler yaralanmalara yol açabilir. Elekroansefalografide 4-7 Hz'lik zemin aktivitesinde beliren 2-3 Hz'lik diken-keskin dalgalar saptanır. Hastaların birinci derece yakınlarındaki artmış epilepsi sıklığı etiolojide genetik nedenleri düşündürtmektedir $(48,49)$.

Miyoklonik-astatik epilepsi tedavisinde ketojenik diyet oldukça etkilidir. Valproik asit ile lamotrijin veya topiramat'ın birlikte verilmesi önemli tedavi seçenekleridir (50). Miyokolonik nöbetleri arttırdığı bilinen karbamazepin, fenitoin ve vigabatrinden sakınılmalıdır.

Hastaların 1/3'ünde bilinç düzeyini etkileyen miyolonik status tablosu gelişir. Bu tablo haftalar boyu sürebilir ve bilişsel etkilenmeye yol açar. Seyire olumsuz etkisi olduğu saptanan diğer etmenler uykudaki yaygın tonik klonik nöbetler ve ailede epilepsi öyküsüdür (51).

\section{Çoklu diken dalga odaklı ağır epilepsi}

Illk kez 1970'lerin sonunda WS ve Lennox Gastaut sendromuna dönüşebilen, nöbet arasında EEG'de bağımsız çoklu diken dalga odaklarının saptandığı ağır bir epileptik durum tariflenmiştir (52). Hastalarda bir çok nöbet tipi görülebilmesine rağmen tonik kasılmalar belirgindir. Etiolojiden özellikle perinatal olaylar sorumlu tutulmuştur. Tipik EEG bulguları nöbetlerin bașlangıcından bir süre sonra ortaya çıkar. Hastalarda psikomotor gerilik belirgindir. Epileptik sendromlar içerisinde değerlendirilmesi gerektiği düşünülen bu durum için önerilen yerleşik tedavi yaklaşımı bulunmamaktadır (53).

Sonuç olarak, çocukluk çağında ortaya çıkan epileptik durumlar arasında EEG bulguları, nöbet tipleri ve hastalık seyriyle farklılık gösteren bir çok epileptik sendrom tanımlanmıştır. Genetik kökenli olduğu düşünülen bu epileptik sendromlar, en sık yenidoğan ve süt çocukluğu döneminde görülür. Ülkemizde genetik incelemeler her zaman istenen düzeyde yapılamasa da, hastanın öyküsü ve klinik izlemle epileptik sendromların tanınabilmesi, uygun tedavi tercihine ve hastaların seyrinin tahmin edilebilmesine olanak sağlar.

\section{Kaynaklar}

1. Muthugovindan D, Hartman L A. Pediatric epilepsy syndromes. The Neurologist 2010; 4: 223-37.

2. Commission on Classification and Terminology of the International League Against Epilepsy. Proposal for revised classification of epilepsy and epileptic syndromes. Epilepsia 1989; 30: 389-99.

3. Wolf P. Basic principles of the ILAE syndrome classification. Epilepsy Res 2006; 70: 20-6.

4. Dehan M, Quillerou D, Navelet $Y$, et al. Convulsions in the fifth day of life: a new syndrome? Arch Fr Pediatr 1977; 34: 730-42.

5. Pryor DS, Don N, Macourt DC. Fifth day fits: a syndrome of neonatal convulsions. Arch Dis Child 1981; 56: 753-8.

6. Goldberg HJ, Sheehy EM. Fifth day fits: an acute zinc deficiency syndrome? Arch Dis Child 1982; 8: 633-5.

7. Miles DK, Holmes GL. Benign neonatal seizures. J Clin Neurophysiol 1990; 7: 369-79.

8. Hirsch E, Velez A, Shellal F, et al. Electroclinical sign of benign neonatal familial convulsions. Ann Neurol 1993; 34: 835-41.
9. Ronen GM, Rosales TO, Connolly M, et al. Seizure characteristics in chromosome 20 benign familial neonatal convulsions. Neurology 1993; 43: 1355-60.

10. Singh NA, Charlier C, Stauffer D, et al. A novel potassium channel gene, KCNQ2, is mutated in an inherited epilepsy of newborns. Nat Genet 1998; 18: 25-9.

11. Singh NA, Otto JF, Dahle EJ, et al. Mouse models of human KCNQ2 and KCNQ3 mutations for benign familial neonatal convulsions show seizures and neuronal plasticity without synaptic reorganization. J Physiol 2008; 586: 3405-23.

12. Ohtahara S, Yamatogi Y. Epileptic encephalopathies in early infancy with suppression-burst. J Clin Neurophysiol 2003; 20: 398-407.

13. Yamatogi Y, Ohtahara S. Early-infantile epileptic encephalopathy with suppression-bursts, Ohtahara syndrome; its overview referring to our 16 cases. Brain Dev 2002; 24: 13-23.

14. Miller SP, Dilenge ME, Meagher-Villemure K, et al. Infantile epileptic encephalopathy (Ohtahara syndrome) and migrational disorder. Pediatr Neurol. 1998; 19: 50-4

15. Dulac O. Epileptic encephalopathy. Epilepsia 2001; 3: 23-6.

16. Komaki H, Sugai K, Maehara T, et al. Surgical treatment of early-infantile epileptic encephalopathy with suppression-bursts associated with focal cortical dysplasia. Brain Dev 2001; 23: 727-31.

17. Ohtahara S, Yamatogi Y. Ohtahara syndrome: with special reference to its developmental aspects for differentiating from early myoclonic encephalopathy. Epilepsy Res 2006; 1: 58-67.

18. Djukic A, Lado FA, Shinnar S, et al. Are early myoclonic encephalopathy (EME) and the Ohtahara syndrome (EIEE) independent of each other? Epilepsy Res 2006; 1: 68-76.

19. Dalla Bernardina B, Dulac O, Fejerman N, et al. Early myoclonic epileptic encephalopathy (EMEE). Eur J Pediatr 1983; 140: 248-52.

20. Murakami N, Ohtsuka Y Ohtahara S. Early infantile epileptic syndromes with suppression-bursts: early myoclonic encephalopathy vs. Ohtahara syndrome. Jpn J Psychiatry Neurol 1993; 47: 197-200.

21. Wirrell E, Farrell K, Whiting S. The epileptic encephalopathies of infancy and childhood. Can J Neurol Sci 2005; 32: 409-18.

22. Cowan LD. The epidemiology of the epilepsies in children. Ment Retard Dev Disabil Res Rev 2002; 8: 171-81.

23. Hrachovy RA, Frost JD. Infantile epileptic encephalopathy with hypsarrhytmia (infantile spasms /West syndrome). J Clin Neurophysiol 2003; 6: 408-25.

24. Ohtsuka Y, Kobayashi K, Ogino T, Oka E. Spasms in clusters in epilepsies other than typical West syndrome. Brain Dev 2001; 23: 473-81.

25. Gaily E, Liukkonen E, Paetau R, et al. Infantile spasms: diagnosis and assessment of treatment response by video-EEG. Dev Med Child Neurol 2001; 10: 658-67.

26. Guzzetta F. Cognitive and behavioral outcome in West syndrome. Epilepsia 2006; 2: 49-52.

27. Appleton RE. West syndrome: long-term prognosis and social aspects. Brain Dev 2001; 23: 688-91.

28. Overby PJ, Kossoff EH. Treatment of infantile spasms. Curr Treat Options Neurol 2006; 8: 457-64.

29. Hancock E, Osborne JP. Vigabatrin in the treatment of infantile spasms in tuberous sclerosis: literature review. J Child Neurol 1999; 14: 71-4.

30. Hancock EC, Osborne JP, Edwards SW. Treatment of infantile spasms. Cochrane Database Syst Rev 2008; 8: CD001770.

31. Kossoff EH, Hedderick EF, Turner Z, et al. A case-control evaluation of the ketogenic diet versus ACTH for new-onset infantile spasms. Epilepsia 2008; 49: 1504-09.

32. Auvin S, Pandit F, De Bellecize J, et al. Benign myoclonic epilepsy in infants: electroclinical features and long-term follow-up of 34 patients. Epilepsia 2006; 47: 387-93.

33. Dravet C, Bureau M, Genton P. Benign myoclonic epilepsy of infancy: electroclinical symptomatology and differential diagnosis from the other types of generalized epilepsy of infancy. Epilepsy Res Suppl 1992; 6: 131-5.

34. Darra F, Fiorini E, Zoccante L, et al. Benign myoclonic epilepsy in infancy (BMEI): a longitudinal electroclinical study of 22 cases. Epilepsia 2006; 5: 31-5.

35. Dravet C, Bureau M. Benign myoclonic epilepsy in infancy. Adv Neurol. 2005; 95: 127-37. 
36. Vigevano F, Fusco L, Di Capua M, et al. Bening infantile familial convulsions. Euro J Pediatrrics 1992; 151: 608-12.

37. Vigevano F. Bening familial infantile seizures. Brain Dev 2005; 27: 172-7.

38. Okumura A, Watanabe K, Negoro T, et al. Ictal EEG in benign partial epilepsy in infancy. Pediatr Neurol 2007; 36: 8-12.

39. Watanabe K, Okumura A. Bening partial epilepsies in infancy. Brain Dev 2000; 22: 296-300.

40. Okumura A, Watanabe K, Negoro T, et al. Long-term follow-up of patients with benign partial epilepsy in infancy. Epilepsia 2006; 47: 181-5.

41. Dravet C, Bureau M, Oguni $\mathrm{H}$, et al. Severe myoclonic epilepsy in infancy: Dravet syndrome. Adv Neurol 2005; 95: 71-102.

42. Ohmori I, Ouchida M, Ohtsuka Y, et al. Significant correlation of the SCN1A mutations and severe myoclonic epilepsy in infancy. Biochem Biophys Res Commun 2002; 295: 17-23.

43. Singh R, Andermann E, Whitehouse WP, et al. Severe myoclonic epilepsy of infancy: extended spectrum of GEFS+? Epilepsia 2001; 42: 837-44.

44. Millichap JJ, Koh S, Laux LC, et al. Child Neurology: Dravet syndrome: when to suspect the diagnosis. Neurology. 2009; 13: e59-62

45. Chiron C, Marchand MC, Tran A, et al. Stiripentol in severe myoclonic epilepsy in infancy: a randomized placebo-controlled syndrome-dedicated trial. STICLO study group. Lancet 2000; 356: 1638-42.
46. Caraballo RH, Cersosimo RO, Sakr D, et al. Ketogenic diet in patients with Dravet syndrome. Epilepsia 2005; 46: 1539-44.

47. Ragona F, Brazzo D, De Giorgi I, et al. Dravet syndrome: early clinical manifestations and cognitive outcome in 37 Italian patients. Brain Dev 2010; 1: 71-7.

48. Doose H. Myoclonic-astatic epilepsy. Epilepsy Res Suppl. 1992; 6: 163-8.

49. Dulac O, Plouin P, Shewmon A. Myoclonus and epilepsy in childhood: 1996 Royaumont meeting. Epilepsy Res 1998; 30: 91-106.

50. Panayiotopoulos CP, Ferrie CD, Knott C, et al. Interaction of lamotrigine with sodium valproate. Lancet 1993; 341: 445.

51. Oguni $\mathrm{H}$, Tanaka T, Hayashi K, et al. Treatment and long-term prognosis of myoclonic-astatic epilepsy of early childhood. Neuropediatrics 2002; 33: 122-32.

52. Yamatogi Y, Ohtahara S. Multiple independent spike foci and epilepsy, with special reference to a new epileptic syndrome of "severe epilepsy with multiple independent spike foci". Epilepsy Res 2006; 70: 96-104.

53. Yamatogi $Y$, Ohtahara S. Severe epilepsy with multiple independent spike foci. J Clin Neurophysiol 2003; 20: 442-8. 